Article

\title{
Cognitive Learning about Waste Management: How Relevance and Interest Influence Long-Term Knowledge
}

\author{
Alexandra Stöckert* (D) and Franz X. Bogner (D) \\ Didactics of Biology, Z-MNU (Centre of Math \& Science Education) University of Bayreuth, NW-1, \\ D-95447 Bayreuth, Germany; franz.bogner@uni-bayreuth.de \\ * Correspondence: alexandra.stoeckert@uni-bayreuth.de
}

Received: 7 March 2020; Accepted: 3 April 2020; Published: 9 April 2020

\begin{abstract}
Efficient waste management is a major prerequisite for reaching sustainability as every one of us produces waste. Thus, educational interventions need to offer promising assistance to reduce individual waste as much as possible to promote environmentally friendly behavior beyond stereotypical notions about waste disposal. Those who know about all facts and circumstances are more likely to correct their behavior. Our hands-on module for fifth graders was designed and implemented to support " $4 R^{\prime}$ ": Reduce, Reuse, Recycle and Recover, by retracing waste's usual journey from collection management to incineration plants. The first module focused on minimizing waste by recycling, reusing and reducing it. The remaining waste was the second module's core, which explained the waste-to-energy path using an age-appropriate functional model of how to effectively generate energy from waste. Both modules are suitable for outreach (informal) implementation as well as for formal classroom learning. The third module comprised either an onsite visit to an incineration plant or a classroom multimedia presentation. A total of 276 fifth graders participated in our three-module implementation study, completing three questionnaire cycles: two weeks before the intervention, immediately after and six weeks later. A subsequent analysis showed a clear pattern: knowledge scores increased immediately after participation and remained constant for at least six weeks. Surprisingly, no significant difference between the multimedia and outreach group appeared. When applying a semantic differential, two response pattern factors, "Relevance" and "Interest", showed significant intercorrelations, as well as positive correlations with knowledge scores. In consequence, learning about waste management matters, and produces short- and long-term effects.
\end{abstract}

Keywords: incineration plant; 4R (reduce, reuse, recycle, recover); assessment; semantic differential; education for sustainability; collaborative learning; outreach learning

\section{Introduction}

Waste is a global manmade problem that pollutes environments on land, air and sea. Everyone produces waste, and, thus, action is required to return to sustainability. The "Fridays for Future" movement shows that young people in particular are deeply concerned about environmental responsibilities, as they face an uncertain future. How waste is being handled may be influenced by social norms and self-confidence [1,2]. Behavioral norms are supposed to support socially acceptable preferences. Many studies have shown, for example, that people in polluted areas tend to pick up waste more often when well-prepared guidance models exist [3,4]. Hasan [5] noted that involving the public in active waste management and raising their awareness is key to solving these problems; using examples from the US, the study found that specific training regarding waste avoidance and recycling, as well as the appropriate adjustment of curricula, have positive effects on raising awareness. Another 
study, in Poland, showed that taking part in an extra waste management modules encourages students to act as multipliers, in that they inspire discussions about waste disposal with their families [6]. This is also true for other studies where students assume multiplicator roles, e.g., in positively influencing parent behavior [7-9]. Hartley, Thompson and Pahl [10] described lessons about waste management as potential ways to solve a global problem since they also have effects beyond school life. Students need to consider the environment worth protecting and to take decisive steps against irresponsible waste disposal; subsequently, they may involve society in realizing and assessing the problem to ensure long-term conscious consumption.

\subsection{Teaching Methods as Triggers for Knowledge Acquisition}

Well-prepared teaching staff are essential for supporting hands-on skills and for initiating individual action. Koehler and Mishra [11], for instance, described good teaching as a complex interaction of three different components: namely, technology, pedagogy and content. Teacher content knowledge, referring to the "amount and organization of knowledge per se in the mind of the teacher" [12] (p. 9), plays a central role. Teachers need to adapt learning contents to respective age groups by correctly delivering preconcepts and involving students from different backgrounds. Moreover, in addition to pedagogical skills, confidently handling media is required, as Koehler and Mishra [11] described with the aspect of "technology". In consequence, classroom competencies within a common sense need to contain four aspects of biology lessons [13]: (1) specialist knowledge (concrete subject contents); (2) gaining knowledge (in developing questions regarding a phenomenon or problem, finding solutions and testing them experimentally); (3) communication (accessing and exchanging information in a subject-related way); and (4) evaluation (which is how to recognize and evaluate biological facts in different contexts). For the knowledge acquisition process, three higher-order levels of abstraction were distinguished: (1) reproduction (content is reproduced unchanged in the same context); (2) reorganization (acquisition in a different context); and (3) transfer (new knowledge is abstracted and applied in a completely different context, mostly abstracted and rearranged). All three combined may contribute to a successful science knowledge construction by considering a balance of all the preconditions.

In summary, inquiry-based science education (IBSE) may unite different aspects of scientific knowledge acquisition, which is comparable to exploring natural phenomena in science [14]. It combines observing phenomena; generating hypotheses and formulating research questions; planning and carrying out appropriate experiments; interpreting data; and reasoning about potential results, as well as presenting them to peers $[15,16]$. As IBSE occurs quite often, a precise definition is required before its implementation in science teaching. The National Science Education Standards (NSES) and Anderson [15] (p. 2) label three essential aspects of IBSE:

1. Scientific inquiry. This part considers different working methods that scientists use to study natural phenomena and explain findings. In our case, the students built a functional model of an incineration plant, did text-guided parts and integrated their solutions to solve the waste problem.

2. Inquiry learning. This is a learning process organized collaboratively with small scientific investigations on various questions, interactive communication and explanations to peers. In our module, students worked collaboratively in pairs, small groups or as a whole class in order to investigate the technological parts of an incineration plant, the circular flow of waste or how to reduce the waste.

3. Inquiry teaching. According to Anderson [15], a central aspect of learning is to investigate, but not to gloss over. According to NSES, the consideration of real-life issues in order to expand knowledge is a central element of good teaching. The teacher in our study acted in the role of a supporter, not as a mere supervisor. 
When using different teaching methods, we need to bear in mind that students do not only learn science at school. It is important to know that experiences, both in school and outside, influence social life [17]. Thus, learning outside and inside of school must be distinguished. Formal learning, with its main focus on cognitive learning success, is the goal of all classroom actions and subsequent assessments [18]. Gerber et al. [19] define informal learning as learning activities outside of formal classrooms. However, definitions are still controversial, as for instance museums offer formal learning without a teacher [20]. Another term may focus on knowledge acquisition, supervised by a teacher but out of school; outreach learning opportunities offer a wide range of possibilities to feasibly impart knowledge to students. Generally, outreach is defined as "the activity or process of bringing information or services to people" [21]. In this context, small hands-on activities are often offered in collaborative actions [22] where experts join the respective activities. Therefore, an in-class learning environment can also be created in learning locations of research centers or universities. In this case, outreach means the combination of real-life elements, constructed learning environments and skills such as teamwork [23].

\subsection{Social Form: Cooperative Learning}

In general, cooperative learning includes supporting each other's learning progress by working together in small groups (mainly used in primary schools). In science education, many different studies investigate cooperative learning and its effects on, for instance, behavior, social interactions and school results in different subjects, although it is controversially discussed why and how this method has positive effects on achievement and which conditions are essentially needed [24-29]. Rohrbeck et al. [30] identifies two aspects of how learning together in groups promotes knowledge growth: (1) the group serves as a teacher who is at the same mental level of development; and (2) the group serves to solve tasks with perseverance and a goal-oriented approach. This is in line with the descriptions of Vygotsky [31] and Piaget [32], who identify social interaction as a root of cognitive development.

Cooperative learning entails students working in groups and communicating with each other. It is, however, not that simple. Johnson and Johnson [33] identify five conditions that enable efficient cooperative learning: " 1 . Clearly perceived positive interdependence. 2. Considerable promotive (face-to-face) interaction. 3. Perceived individual accountability and personal responsibility to achieve the group's goals. 4. Frequent use of relevant interpersonal and small-group skills. 5. Frequent and regular group assessments regarding group capabilities to improve the group's future effectiveness (p. 2)". In consequence, combining hands-on learning with cooperative learning often shows higher scores for cognitive achievement than normal classes [34]. A combination of both methods might help to motivate and support low achievers. Such synergies are also reported by Marth and Bogner [35] as well as Kyndt et al. [36]. However, just a few teaching modules covering all waste disposal processes exist, e.g., Grodzińska-Jurczak et al. [6], which is why our teaching module intended to provide a holistic overview for various age groups and to focus on different possibilities of waste treatment (" $4 \mathrm{R}$ ": Reduce, Reuse, Recycle and Recover). However, it is not only important how knowledge is communicated; individual preferences also play an important role.

\subsection{Interest and Relevance as Components of Motivation}

Interest was described by Palmer [37] as a form of motivation that occurs in special situations on a short-term basis and initiates as well as maintains learning processes. As an important component for motivation, it has the power to effectively influence behavior. Since different studies described 'interest' as a strong variable to influence learning, attention and goal finding [38], it can be regarded as a person-object-related relationship [39] playing a directive role to naturally approach activities [22]. Overall, two forms of interest are important: (1) individual (trade) interest, described as long-term interest and preference for a particular subject area [40]; and (2) situational (state) interest, described as a short-term emotional state that arises from situational stimuli [41-44]. The latter is considered to contain two phases. In the first part, attention is aroused by the environment, and in the second, 
attention is maintained [45]. For the latter, Mitchell [46] describes another classification of interest, distinguishing between catch- and hold-phases. He attributed the ability to catch interest to the social form or special methods, thereby stabilizing situational interest into the hold and phase levels and supporting special interest in a certain topic. Therefore, situational interest may play an important role in the development of individual interests. Palmer [37] also identifies different sources that arouse interest within this context: novelty, physical activity, social involvement, surprise and choice. Therefore, teaching should initiate situational interest to achieve long-term interest that is sufficient for learning processes [44]. However, it is not only subject choices that matter; attitudes and interest also influence learning success, as do social forms and chosen methods [47].

Relevance is the extent to which a judgment has considerable consequences for personal needs, personal goals or personal career [30,31]. Frymier and Shulman [48] describe it as the learning content which is considered useful for personal career paths. In addition, besides immediacy, relevance is provided as closely related to state motivation. Gilman and Anderman [49] see relevance as important to aligning a curriculum with students' interests, and consider it essential to ensuring an optimal learning process. Thus, knowledge about aspects of the content that will be relevant from students' point of view is important. According to Albrecht and Karabenick [50], students need to recognize the importance of instruction in a respective subject and also value social relevance.

These studies identify relevance and interest as very important components and conditions of motivation. According to Alexander [51], social psychologists see relevance as the connection between extrinsic and intrinsic motivation to perform in a particular area. The National Research Council [52] even suggests that an educational program should not only take into account the aspect of relevance, but also build on the cultural and personal experiences of students. This allows identification with everyday learning situations outside of school. Newby [53] positively links relevance with learning time and motivation as such. Therefore, teaching methods should support motivation and promote relevance and interest.

\subsection{Focus of the Study}

Based on a newly developed teaching module about waste management., our research objectives were three-fold: (1) to evaluate the knowledge acquisition in our collaborative hands-on-module, and to evaluate our ad hoc instrument to monitor knowledge acquisition; (2) to determine the impact on short-term and delayed effects of knowledge acquisition in an outreach learning location compared to classroom lessons; and (3) to determine the relevance and interest involved with cognitive learning (classroom vs. outreach).

\section{Procedures and Methods}

\subsection{Participants}

Overall, 276 fifth graders ( $M \pm S D: 10.2 \pm 0.42$ years) participated in our study. All schools used in the study were located in Bavaria, in both rural and urban regions. Teachers officially registered their students before participating in our module. Parents gave their written consent.

\subsection{Intervention Design}

Our intervention was designed as a IBSE [14] module, combining hands-on and peer-guided activities in class or out-of-class. It followed the Declaration of Helsinki, and its application was approved by the Bavarian Ministry of Education. Our activity was planned flexibly and was able to be applied in conventional classrooms or at an out-of-class site. The module about waste-management and the "4R" (Reduce, Reuse, Recycle, and Recover) was designed for three school lessons (135 min), with an optional 60-min visit to an incineration plant. The impact of the increasing amounts of waste, in combination with individually generated solutions, were key to the first module. Students worked in peer groups to retrace the waste cycle and to compare it with natural processes of decomposition. 
The second module introduced the incineration of waste that had resisted any recycling procedures. It explained the process of waste incineration, and the fact that the emissions of particles or poisonous gases are prevented due to filter applications. Students learned technical terms about energy ranges and the generation of electricity using steam (produced by incineration). These theoretical foundations were then put into practice when students constructed a miniature functional model of a waste power plant. Successfully built models illuminated an LED when tested. Additionally, a subsample completed the optional onsite visit in an incineration plant in order to provide a link to real-life objects (Figure 1). Optionally, a virtual visit was prepared as a film for the remaining subsample.

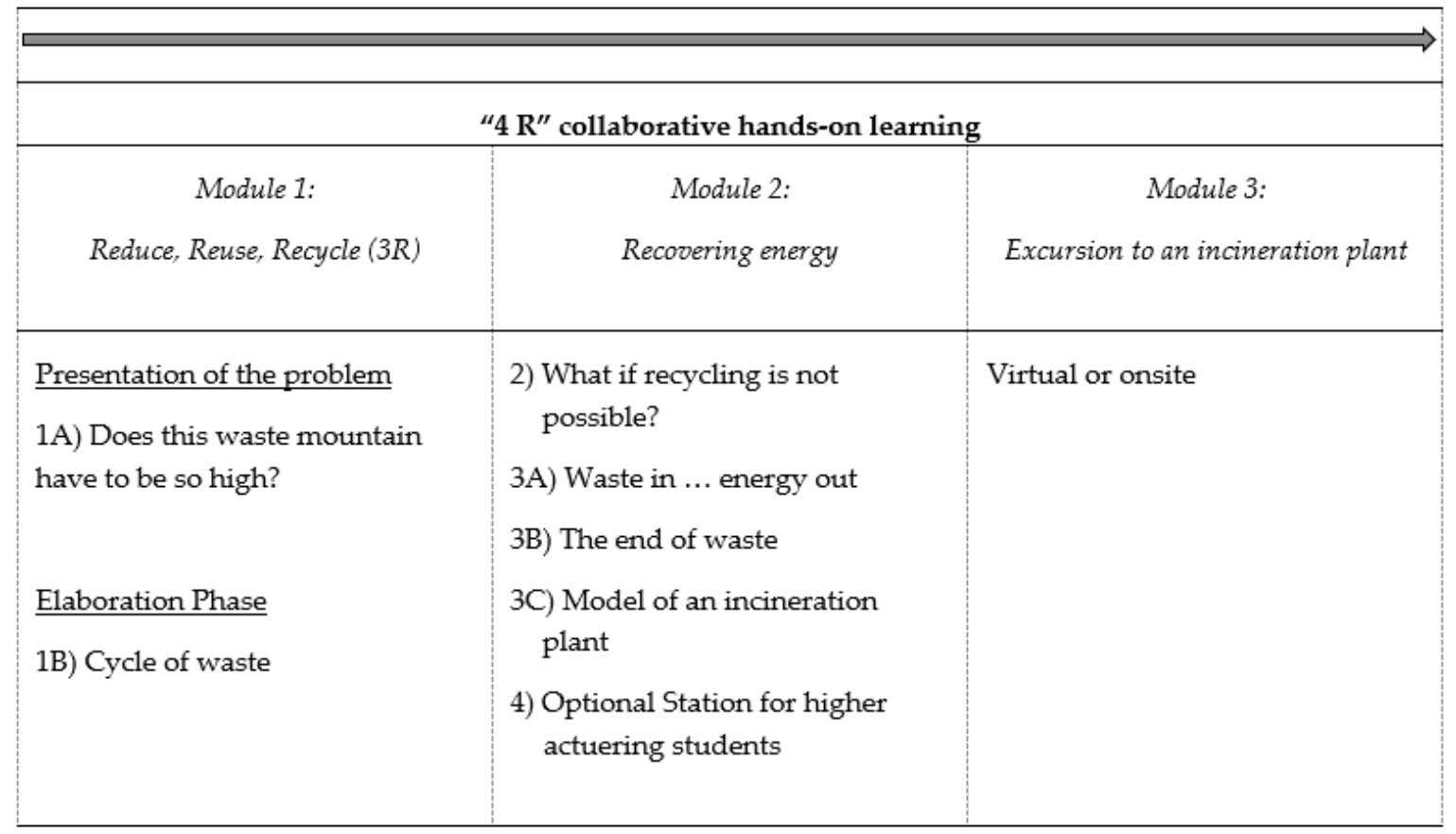

Figure 1. Different stations of the three modules of our " $4 R$ " intervention.

Students collaborated in pairs or small groups, guided by a workbook and instructed by the same teacher. After a short introduction, students worked mostly independently. In order to ensure efficiency, all steps were available six times, including the solutions and supplementary tools. Students self-assessed their results by comparing them with the teacher's desk booklet.

\subsection{Test Design and Instruments}

To assess prior knowledge, a paper pencil test (T0) was completed two weeks before the intervention. After participating in our module, a post knowledge test (T1) was applied, and six weeks later a retention test (T2) was administered (see Figure 2). Waste management unites different aspects of science (biology, physics, and chemistry), and this was reflected in our knowledge questionnaire. The knowledge test contained 13 items, assessing knowledge about waste management and the technical function of incineration plants. Examples are given in Table 1. For each testing point, questions and answer possibilities were mixed and randomly arranged. Knowledge scores were based on sum scores $(1=$ correct, $0=$ incorrect answer). Secondly, to monitor individual willingness to take action, a semantic differential was applied with response options to two antithetic possible choices [54]. 


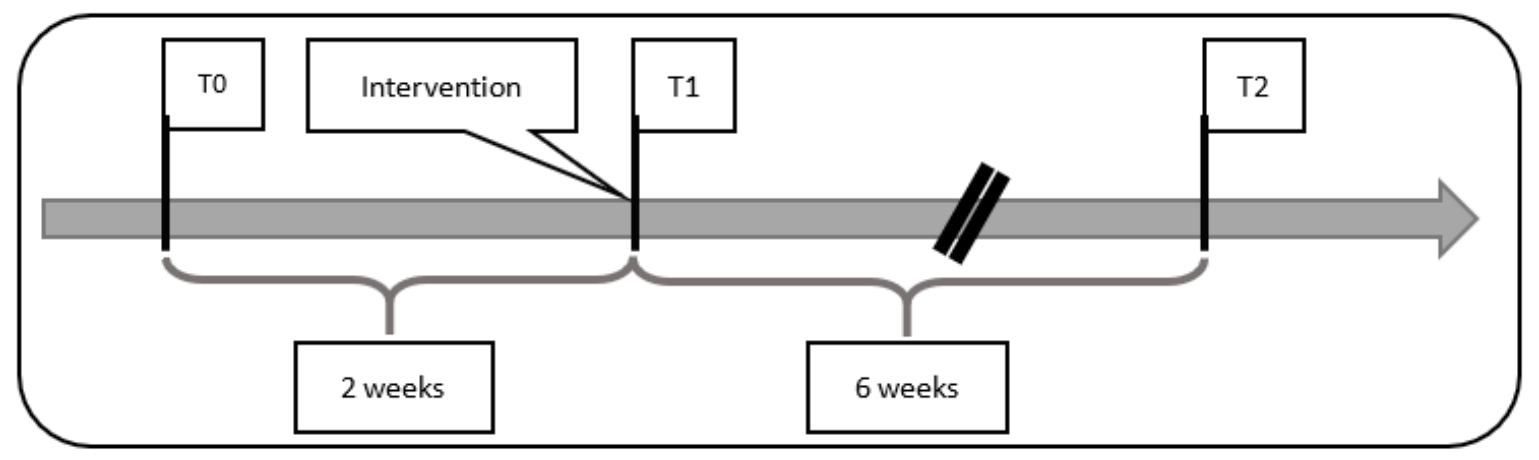

Figure 2. Schedule of the questionnaire implementation at three testing points. T0 assesses prior knowledge, $\mathrm{T} 1$ assesses the knowledge directly after the intervention and $\mathrm{T} 2$ assesses retention after six weeks.

Table 1. Example items of the knowledge test.

\begin{tabular}{|c|c|}
\hline \multicolumn{2}{|c|}{ Example Questions } \\
\hline $\begin{array}{l}\text { W1_1 } \\
\text { What is left when incinerating residual waste in the } \\
\text { waste-to-energy plant? } \\
\text { (a) particulate matter } \\
\text { (b) slag } \\
\text { (c) nothing } \\
\text { (d) soot }\end{array}$ & $\begin{array}{l}\text { W1_17 } \\
\text { A generator turns ... } \\
\begin{array}{l}\text { (a) } \ldots \text { Kinetic energy into heat energy. } \\
\text { (b) } \ldots \text { Heat energy into electrical energy. } \\
\text { (c) } \ldots \text { Kinetic energy into electrical energy. } \\
\text { (d) } \ldots \text { Heat energy into kinetic energy. }\end{array}\end{array}$ \\
\hline $\begin{array}{l}\text { W1_3 } \\
\text { The waste-to-energy plant supplies the people in the } \\
\text { area with ... }\end{array}$ & $\begin{array}{l}\text { W1_16 } \\
\text { Which transport packaging for your purchases } \\
\text { generates the least amount of waste? }\end{array}$ \\
\hline $\begin{array}{l}\text { (a) } \ldots \text { Energy for power generation. } \\
\text { (b) } \ldots \text { Water for toilet flushing. } \\
\text { (c) } \ldots \text { Soot for tire production. } \\
\text { (d) } \ldots \text { Garbage bins for disposal. }\end{array}$ & $\begin{array}{l}\text { (a) paper bag } \\
\text { (b) plastic bag } \\
\text { (c) textile bag } \\
\text { (d) cardboard box }\end{array}$ \\
\hline
\end{tabular}

The method of applying semantic differentials can be useful to describe individual preferences, identifying tendencies involved in emotions or attention regarding an object [55,56]. As a tool to quantitatively analyze word meanings, originally developed by Osgood [57], it was chosen for application in our settings and applied by focusing on the two variables "Interest" and "Relevance". Both are supposed to support knowledge acquisition as they are often also used in connection with motivation $[48,50,58]$. Participants were subsequently asked, based on a five-digit Likert scale with respective adjectives ("boring-fascinating", "unnecessary-necessary") adapted from Schönfelder and Bogner [11,58], for attitudes regarding waste to energy plants ("I think a waste to energy plant is ... "). Thereby, the relevance of and the interest in a waste to energy plant were measured. Most of our study took place in the classroom with a virtual tour through the incineration plant. Only a small subsample ( $N=47$ ) completed the onsite module. A test/retest sample $N=52$ with students $M=11.08$ completed the knowledge test without taking part in our intervention.

\subsection{Statistical Analysis}

Statistical analyses were conducted with IBM SPSS Statistics 24.0 (IBM, Armonk, NY, USA). All in all, 276 complete data sets were assessed. Due to the sample size, the central limit theorem is implied which means it can be calculated with parametric tests [59]. Difficulty indices of knowledge items were determined by relating the number of correct answers to the total number of participants. Responses 
were, thereby, recoded as (1) for correct and as (0) for incorrect answers. For reliability analysis, Cronbach's alpha was calculated to assess the internal consistency of the knowledge questionnaire which consists of 13 multiple-choice questions, each offering four possible answers. The internal consistency of the questionnaire was acceptable, with Cronbach's alpha for T2 $(\alpha=0.617)$.

Sum scores were formed for each knowledge item and then analyzed, using repeated measurement ANOVA to detect knowledge differences between the three different test times. Post-hoc testing with Bonferroni correction was used for pairwise comparison of the different testing times (T0, T1 and T2).

\section{Results}

\subsection{Item Difficulties}

Due to the subject dependency, knowledge assessment required an ad-hoc instrument. The relevant criteria showed item difficulties ranging from 0.06 to 0.84 , with higher scores indicating simple, easy to answer items and low scores indicating difficult items. The item spectrum (Figure 3) shows their spread over the entire range. Taking hierarchy response patterns into consideration, easy questions are associated with more reproduction of given information, whereas questions of medium difficulty indicate reorganization and difficult questions, suggesting transfer of knowledge (see Table 1). Response patterns of the preknowledge test calculated with Kolmogorov-Smirnov-Test show a normal distribution $(p=0.20)$ of the item difficulties.

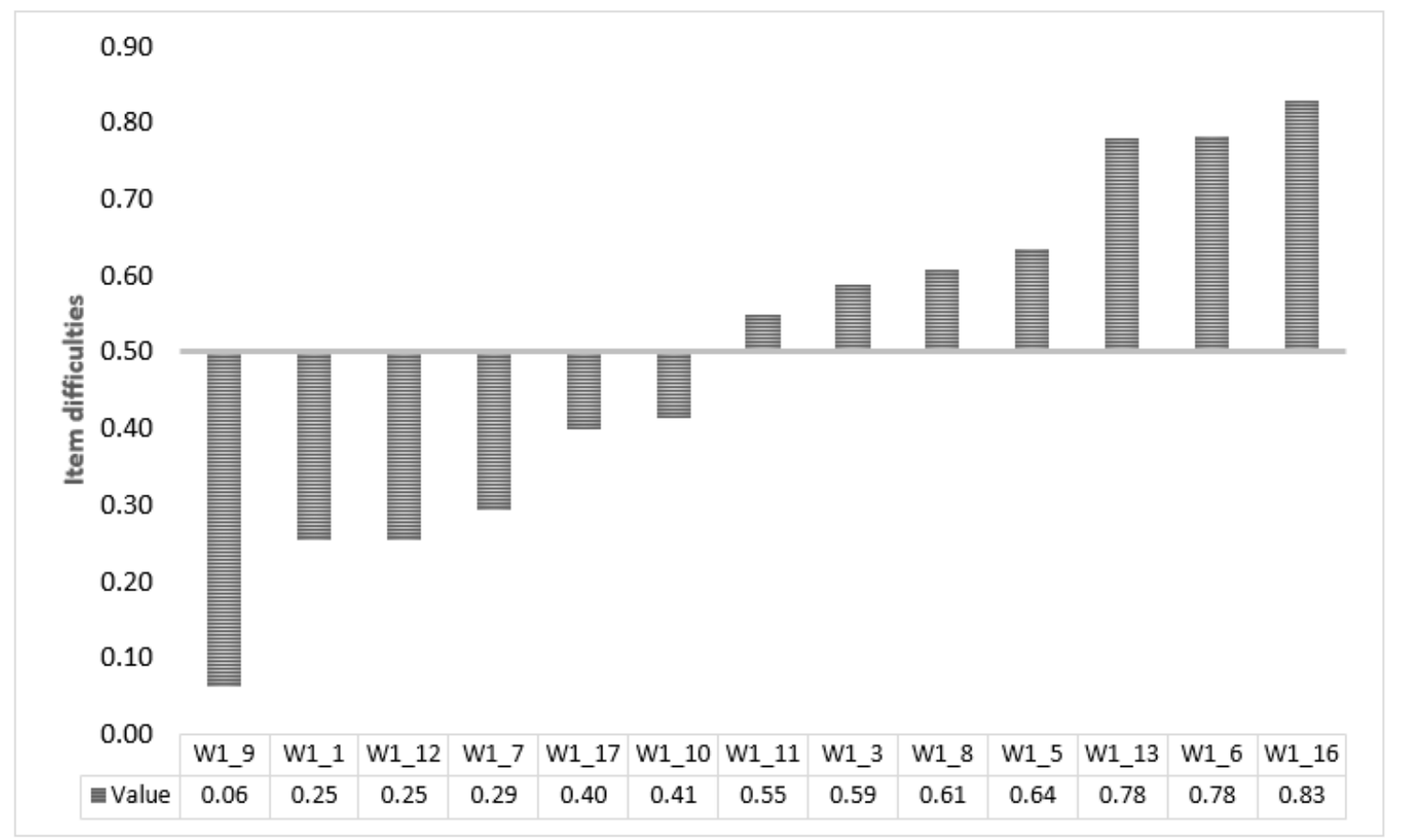

Figure 3. Item difficulties displayed for all 13 items (low scores indicate difficult items, high scores easy ones).

\subsection{Knowledge Acquisition in and beyond Intervention}

Knowledge acquisition peaked at $\mathrm{T} 1(M=8.91 ., S D=2.24)$ for the classroom sample $N=229$ with a marginal drop after six weeks $\mathrm{T} 2(M=8.55, S D=2.37)$. Nevertheless, the low original pretest scores T0 $(M=6.32, S D=2.25)$ were never reached again. The Huynh-Feldt adjustment was used to correct violations of sphericity as $\varepsilon>.75$. In combination with repeated measures, ANOVA analysis showed different achievement levels between the three testing times, $F(1.94,900.49)=18.6 .28$, $p<0.001$, partial $\eta^{2}=0.45$. Bonferroni-adjusted post-hoc analysis revealed a significant increase in knowledge scores from T0 to T1 (MD $=-2.59, p<0.001^{* * *}, 95 \%$ - CI $\left.[-2.95,-2.23]\right)$ as well as from T0 
to T2 $\left(M D=-2.23, p<0.001^{* * *}, 95 \%-\mathrm{CI}[-2.60,-1.85]\right)$ with pairwise comparison for all three testing schedules. A difference between T1 to T2, however, did not appear. Our outreach subsample $N=47$ also reached its highest knowledge scores at $\mathrm{T} 1(M=8.43, S D=1.75)$ even with an increase after six weeks T2 $(M=8.79, \mathrm{SD}=1.65)$ compared to pretest T0 $(M=6.98 ., S D=1.62)$. Here, Huynh-Feldt adjustments also were applied as $\varepsilon>.75$, detecting significant differences between the three testing schedules, $F(2.00,86.09)=25.18, p<0.001$, partial $\eta^{2}=0.35$. Bonferroni-adjusted post-hoc analysis was applied to all and revealed a significant increase in knowledge scores from T0 to T1 $(M D=-1.45$, $p<0.001^{* * *}, 95 \%$ - CI $\left.[-2.11,-.78]\right)$ as well as from T0 to T2 (MD $=-1.81, p<0.001^{* * *}, 95 \%-$ CI $[-2.49,-1.13]$ ) (Figure 4$)$ with pairwise comparison. T1 to T2 scores did not differ. Similarly, the test/retest groups (T0: $M=7.31, S D=2.00, \mathrm{T1}: M=6.69, S D=2.339$ ) did not differ.

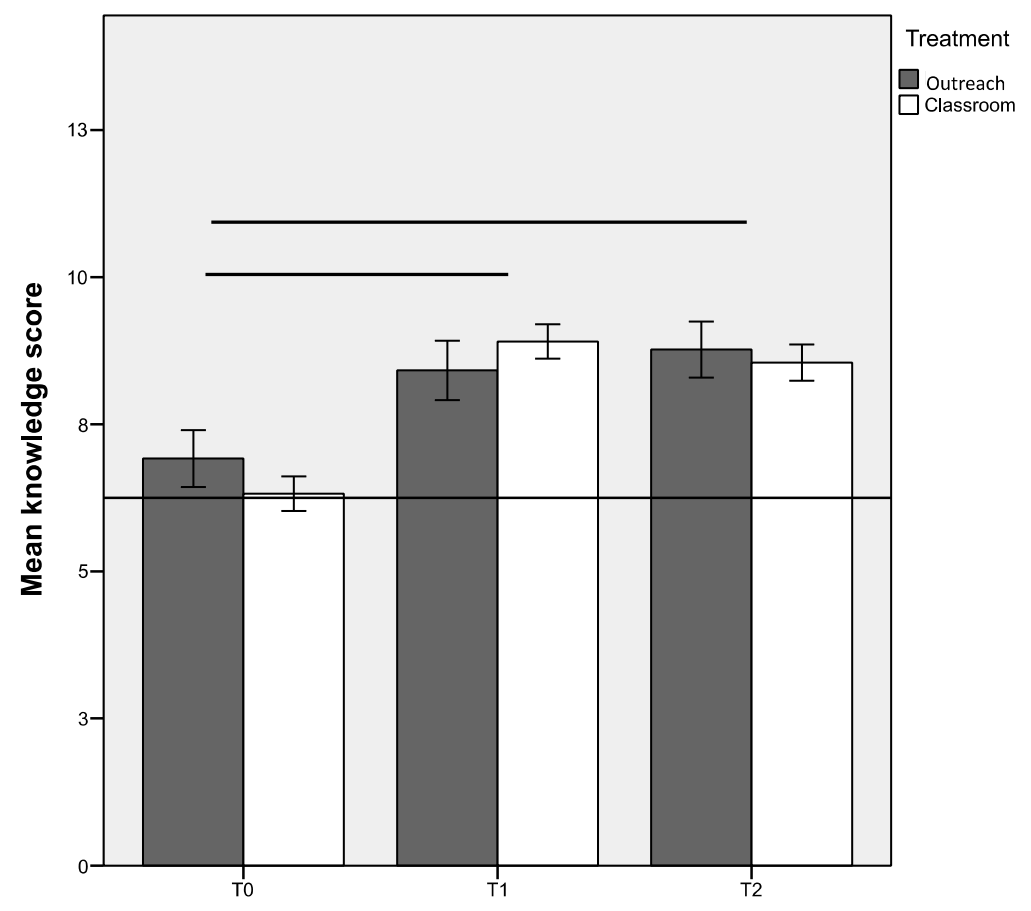

Figure 4. Mean knowledge scores at three testing points of the outreach and classroom treatment. Bars are 95\% confidence intervals. T0: prior knowledge; T1: postknowledge test after completing our module; T2: retention test after six weeks. P-value indicates the significance level. T0 to T1 and T0 to T2 differed significantly $(\mathrm{p} \leq 0.001)$.

\subsection{Semantic Differential Scores}

A principal-axis factor analysis extracted two factors for the seven-word pairs of the semantic differential. Both could be interpreted and summarized as follows: "Relevance" contains three-word pairs, "Interest" four. The Kaiser-Meyer-Olkin measure of sampling adequacy KMO (Kaiser, 1970) yielded a score of 0.84 . As the acceptable limit is defined at 0.5 [59], our score drastically outnumbered this limit. The Bartlett's test of sphericity was significant $(p<0.001)$, indicating correlations between items were sufficient for performing factor analysis. An examination of Kaiser's criteria and the scree plot yielded empirical justification for retaining two factors and explained $70.69 \%$ of the total variance. Table 2 shows factor loadings after oblimin rotation. As a predictor for reliability [60], Cronbach's $\alpha$ scored "Relevance" with 0.85 and 0.81 for "Interest". 
Table 2. Loading pattern of the exploratory factor analysis of the semantic differential.

\begin{tabular}{ccc}
\hline & Factor Loadings: Relevance & Factor Loadings: Interest \\
\hline worthless/worthy & 0.807 & \\
unimportant/important & 0.802 & \\
needless/needed & 0.772 & 0.738 \\
uncool/cool & & 0.701 \\
nasty/likeable & & 0.655 \\
uninteresting/interesting & & 0.600 \\
boring/fascinating & & \\
\hline
\end{tabular}

An independent t-test showed differences between the two factors of the semantic differential regarding the authentic outreach and multimedia group (Figure 5). We found statistically significant differences between the factor "Relevance" of the onsite group and the classroom group $(95 \%-C I[0.25,0.84])$, with lower scores for the classroom group $t(299)=3.62, p<0.001$. The same effect could be observed for the factor "Interest" (95\%-CI [0.13, 0.69]), with lower preferences for the classroom group $t(299)=2.89, p<0.001$.

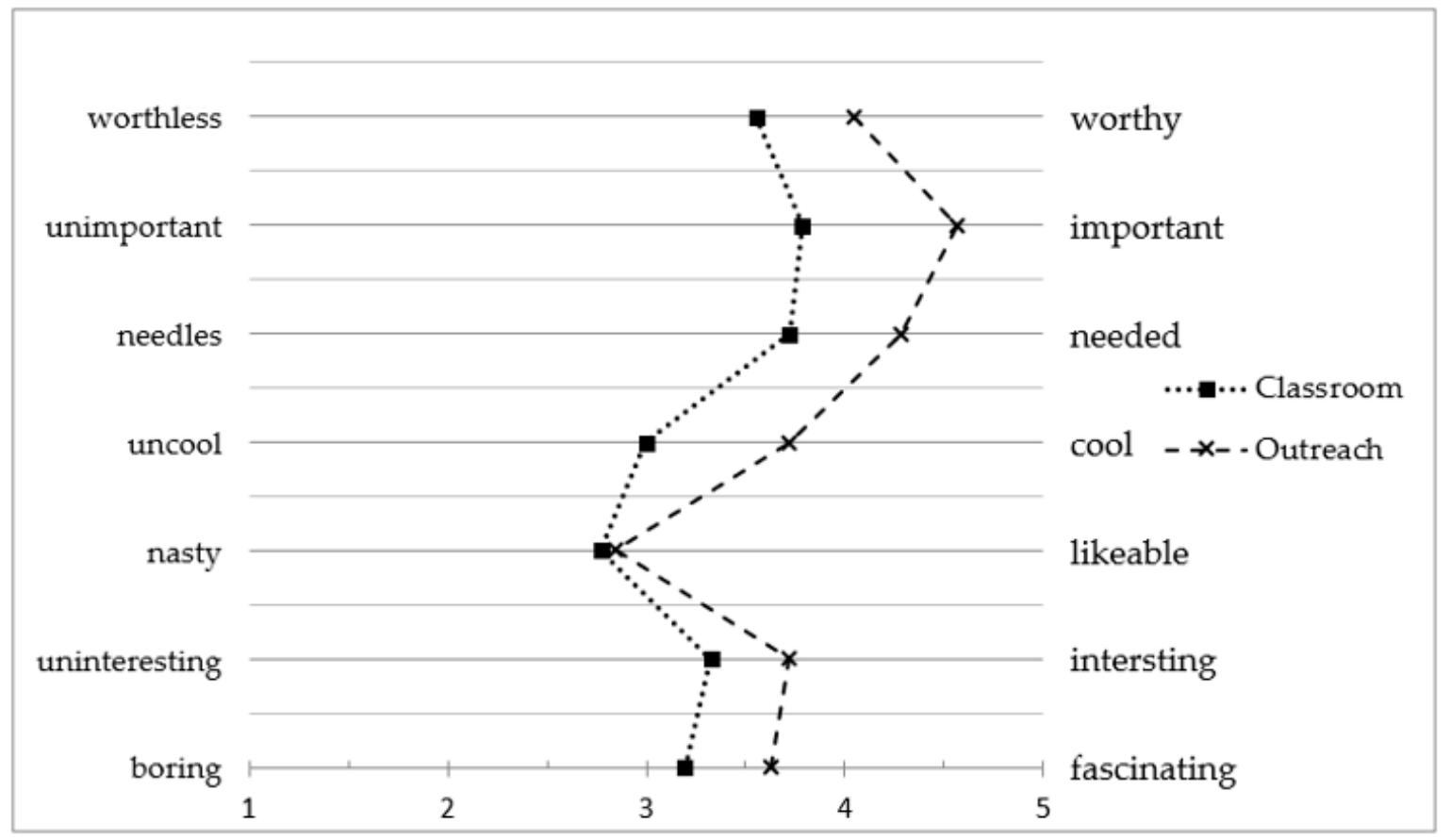

Figure 5. Semantic differential scores of outreach and classroom groups of each word pair.

\subsection{Correlation between Semantic Differential and Knowledge Acquisition}

"Interest" and "Relevance" correlated with knowledge scores and intercorrelated with each other (Table 3). Furthermore, a positive correlation appeared between the retention test T2 and the factors "Interest" as well as "Relevance".

Table 3. The semantic differential in correlation with the knowledge acquisition of the main sample.

\begin{tabular}{ccccccc}
\hline & & \multicolumn{2}{c}{ Semantic Differential: } & \multicolumn{3}{c}{ Knowledge: } \\
\cline { 3 - 6 } & & Interest & Relevance & T0 & T1 & T2 \\
\hline \multirow{2}{*}{ Interest } & Sig. & & $<0.0001$ & n.s. & n.s. & $<0.0001$ \\
& Corr. & 1 & $0.581^{* * *}$ & & & $0.202^{* * *}$ \\
& Sig. & $<0.0001$ & 1 & n.s. & n.s. & $<0.0001$ \\
& Corr. & $0.581^{* * *}$ & & & & $0.255^{* * *}$ \\
\hline
\end{tabular}




\section{Discussion}

The highlights of the study are clear: individual "Interest" and "Relevance" clearly correlated with cognitive learning; and the collaborative hands-on module supported knowledge acquisition, even for some delayed duration, in both formal and outreach settings. The following chapters put the outcomes into relation with the literature.

\subsection{Cognitive Learning Context}

We were surprised by the similarity between the short-term and delayed effects on knowledge acquisition in this study. It seems our participants did not forget their newly acquired knowledge. The learning location seemed to play a subordinate role, since classroom and outreach onsite instruction resulted in similar learning effects. Bogner and Fremery [61] had shown similar results in similar circumstances (of an incineration plant) regarding the short- and delayed effects at knowledge acquisition, examining the three dimensions of knowledge [61]. One reason for having obtained such a surprising result might be the link between situational emotions like interest or relevance [25].

The knowledge questions seemed well chosen for the study, as a relevant increase in knowledge before and after the educational measure became apparent, which is in line with another study of Marth and Bogner [35]. Item difficulties were well-balanced and showed a normal distribution of the items; easy and difficult questions had the same ratio. A reason for successful learning might be the selection of learning activities which, besides a focus on knowledge acquisition, offer methodological variation, according to Tennyson and Rasch [62], and altogether benefit knowledge acquisition.

Consequently, our interactive module about waste management, including the main functions of an incineration plant, had a significant impact on mid- and delayed effects on knowledge, regardless of whether the module was delivered onsite or virtually [35]. This is in contrast to several earlier studies regarding waste and environment $[27,61]$ which reported long-term learning only as a success of outreach modules.

\subsection{Interest and Relevance}

There is a strong link between relevance and interest in influencing delayed effects on knowledge. Looking at individual interest, Schiefele [58] describes two components: the emotional part, focusing on feelings or emotions to an object or topic; and the value-related part, considering the personal relevance and attachment to an object. As the tool of a semantic differential frame is considered to capture feelings about a selected subject and to provide information about interest, we consider both to be predicting variables of retention achievement. Renninger et al. [40], for instance, observed a wide-ranging knowledge if interest was present. Müller [63] further describes interest as correlating with willingness to learn and learning strategies, which in our case would also provide an explanation for the retention performance after six weeks. Furthermore, the aforementioned factors identified by Palmer [37] (i.e., novelty, physical activity, social involvement, surprise and choice) have been implemented in our teaching module, not only offering new content but also social and physical action. An incineration plant in a neighborhood, for instance, may contain social involvement in relation to a learning object which may possibly explain the link between "relevance" and "interest". This is in line with Värlander [64] who postulates that emotions are a natural and important part of learning, whereas retention and attention problems are reported to be related to boredom [43,65]. Classroom intervention may already indicate a medium interest, whereas an outreach visit may further increase interest scores. This small difference could be an indication that outreach teaching increases interest in the subject matter, and thus promotes retention performance. Furthermore, applying an inquiry method seems to involve both interest and relevance. In this context, Gibson and Chase [66] reported higher interest scores after an inquiry-based session, recommending research-based teaching to encourage interest and motivation. 


\subsection{Long-Term Knowledge}

Knowledge acquisition seemingly does not depend on the length of an intervention, as short units also have positive effects on long-lasting knowledge [25,67]. Short lesson units are also considered to be more practicable, since it is easier for teachers to integrate them into school curricula. Furthermore, Bogner [68] showed that short interventions can positively influence knowledge over a period of four weeks. This is also in line with other studies that have shown this effect over a period of six weeks $[35,69]$. All studies display a clear increase in knowledge after such interventions. This was also true for our teaching module. Furthermore, it seems to be relevant who is teaching and where the information is being distributed. According to Johnson \& Manoli [70], extracurricular learning programs also lead to enhanced environmental awareness with related increase in knowledge after several weeks [71,72]. Stein, Isaacs and Andrews [73] describe professional knowledge transfer as helpful for students to better understand and retain what they have learned. Regarding knowledge acquisition, in our intervention approximately 6.32 of 13 questions were correctly answered at testing time T0. Immediately afterwards, our classroom group was able to answer about 8.91 questions, and after six weeks, about 8.55 questions out of 13 . This result can also be obtained in other half-day lessons about waste with a permanent increase in knowledge [61,69] and is also in line with other studies $[71,74,75]$. However, students usually have a significant increase in knowledge shortly after the intervention followed by a substantial drop afterwards [69], but never below preknowledge levels. Such findings are common not only for a period of six weeks but sometimes also for longer periods e.g., more than one year [26,35]. Educational activities in a certain subject area thus improve knowledge, and with some losses may retain it even for long periods. In our case, a lack of any such drop was apparent and quite surprising, since an almost constant level of knowledge scores remained. Possible reasons for this remarkable knowledge acquisition need closer argumentation regarding e.g., teaching styles (IBSE, cooperative learning) or formal/informal contexts.

A potential reason for delayed effects at knowledge acquisition and the low drop rates of our module could be, inter alia, our use of IBSE as a learning strategy. When students are guided step by step through an intervention they are more likely to acquire scientific knowledge [17]. They autonomously formed a functional model of an incineration plant, a replica of the original, and thus developed an understanding of scientific work, which enabled problem-solving skills and creative thinking. These variables are important features of IBSE because finding meaningful explanations is key for learning science [14]. In consequence, the IBSE method is supposed to help develop knowledge from the exploration of scientific phenomena [14]. Furthermore, an exchange of knowledge between peers allows the transfer of knowledge within previously unknown areas. This is also a central point of active learning [76]. IBSE is, therefore, not the only condition for delayed effects on knowledge acquisition, as different teaching methods can achieve comparable results [15]. Another reason for retaining knowledge could be the small group size of a maximum of 3-4 students. By working together, students achieve common success with common "learning goals" [77]. Blumenfeld et al. [78] mention in this context that creating a good learning environment is not enough; the willingness to supplement missing information is also required, whereby possible solutions and their verification/falsification is vital to critically evaluate their results. In our module, students were encouraged to learn hands-on and to compare solutions independently with the solutions provided. There was no need to fear an evaluation via grades or immediate feedback by a positive result, as in our case the LED lighting. Graham and Golan [79] note that students focusing on self-improvement rather than competition seem to have better retention performance, which could have also influenced the here-assessed intervention.

Interpersonal relationships also play an important role in group learning. Accomplishing a task together positively influences STEM-specific self-concepts [80]. Another probable reason for delayed effects on knowledge acquisition is our hands-on design. This is also in line with the constructivist learning theory. According to Mayer [81], hands-on activities support a learning process due to independent thinking and problem-solving. These results are similar to those of e.g., Bissinger \& Bogner; Marth \& Bogner [35,75] who also observed a long-term increase in knowledge similar to 
our post-test. Good retention performance, in our case achieved by half-day intervention, is also consistent with the observations of. The lack of difference between a formal classroom group and an outreach group requires further in-depth discussion as outreach learning normally is considered more beneficial than classroom learning. Therefore, it can be assumed that for our subject area, outreach is not necessary to ensure good knowledge acquisition. However, it is conceivable that outreach will increase interest and relevance, but not significantly in our case (Figure 5). A simple explanation could also be that a visit to the incinerator is about something new, which in itself increases the interest and the novelty effect takes effect [82].

\subsection{Limitations of the Study}

Limitations often originate in small sample sizes, which is also true in our case. Another concern often is the chosen age group, which in our case was defined by the existing syllabus. Clearly the older the participants, the more sophisticated the lesson designs could be. The best designed modules are useless when a teacher cannot integrate an issue into a curriculum.

Although our knowledge test only assessed subject knowledge, our teaching module also was supposed to promote other aspects—such as communication, social skills or how to deal with teaching material—that were not assessed in our case. These are important learning objectives that should be learned in school, but we limited ourselves to the collection of knowledge, as this corresponds to the standardized performance measurement at school.

\section{Conclusions}

In summary, outreach learning adds substantial value to school life but apparently is not preconditional to achieving better knowledge outcomes. A good classroom learning environment also allows successful learning beyond mere short-term peaks. Soft skills such as interest seem to contribute as important players and to network newly acquired knowledge horizontally and vertically. Similarly, the chosen method of inquiry-based learning seems to positively influence retention efficiency. Additionally, the condition remains important that for a learner, some things are worth being learned. Of course, our intervention is only one problem-oriented possibility to address the waste problem with its technical solution possibilities, but it offers an approach for making a topic relevant for students and integrating it into a school context. Nevertheless, it embeds a vital issue into school contexts as other current aspects do such as microplastics, GMOs or very recently the coronavirus pandemic.

Author Contributions: A.S. collected the data, assured the data curation and initiated the first draft. F.X.B. secured the funding acquisition, the project administration, and supervision. Both authors commented on and approved the manuscript. All authors have read and agreed to the published version of the manuscript.

Funding: This research was funded by the OSOS-Project (European Union Grant Agreement, [No.741572]) as well as the University of Bayreuth granted financial support. Additionally, the German Research Foundation (DFG) and the University of Bayreuth in the funding program Open Access Publishing under grant agreement no. LA 2159/8-6 funded this publication. The funders had no role in the design of the study, in the collection, analyses, or interpretation of data, in the writing of the manuscript, or in the decision to publish the results. This article reflects only the authors' views. The funders are not liable for any use that might be made of the information contained herein.

Acknowledgments: We appreciate the support of the students and the teachers. The Bavarian Ministry of Education had approved the used questionnaires (KMS: IV.8-BO5106/171/9).

Conflicts of Interest: The authors declare that there is no conflict of interest regarding the publication of this paper.

\section{References}

1. Cialdini, R.B.; Reno, R.R.; Kallgren, C.A. A Focus Theory of Normative Conduct: Recycling the Concept of Norms to Reduce Littering in Public Places. J. Personal. Soc. Psychol. 1990, 58, 1015. [CrossRef]

2. De Kort, Y.A.W.; Mccalley, L.T.; Midden, C.J.H. Persuasive Trash Cans Activation of Littering Norms by Design. Environ. Behav. 2008, 40, 870-891. [CrossRef] 
3. Cialdini, R.B. Crafting Normative Messages to Protect the Environment Social Psychology Crafting Normative Messages to Protect. Curr. Dir. Psychol. Sci. 2003, 12, 105-109. [CrossRef]

4. Schultz, P.W.; Bator, R.J.; Large, L.B.; Bruni, C.M.; Tabanico, J.J. Littering in Context: Personal and Environmental Predictors of Littering Behavior. Environ. Behav. 2013, 45, 35-59. [CrossRef]

5. Hasan, S.E. Public Awareness Is Key to Successful Waste Management. J. Environ. Sci. Heal. Part A Toxic/Hazard. Subst. Environ. Eng. 2004, 39, 483-492. [CrossRef] [PubMed]

6. Grodzińska-Jurczak, M.; Bartosiewicz, A.; Twardowska, A.; Ballantyne, R. Evaluating the impact of a school waste education programme upon students' parents' and teachers' environmental knowledge, attitudes and behaviour. Int. Res. Geogr. Environ. Educ. 2003, 12, 106-122. [CrossRef]

7. Ballantyne, R.; Fien, J.; Packer, J. School Environmental Education Programme Impacts upon Student and Family Learning: A case study analysis. Environ. Educ. Res. 2001, 7, 23-37. [CrossRef]

8. Evans, S.M.; Gill, M.E.; Marchant, J. Schoolchildren as educators: The indirect influence of environmental education in schools on parents' attitudes towards the environment. J. Biol. Educ. 1996, 30, 243-248. [CrossRef]

9. Gallagher, J.; Wheeler, C.; McDonough, M.; Namfa, B. Sustainable Environmental Education for a Sustainable Environment: Lessons from Thailand for Other Nations. Water Air Soil Pollut. 2000, 123, 489-503. [CrossRef]

10. Hartley, B.L.; Thompson, R.C.; Pahl, S. Marine litter education boosts children's understanding and self-reported actions. Mar. Pollut. Bull. 2015, 90, 209-217. [CrossRef]

11. Mishra, P.; Koehler, M.J. Technological Pedagogical Content Knowledge: A Framework for Teacher Knowledge. Teach. Coll. Rec. 2006, 108, 1017-1054. [CrossRef]

12. Shulman, L.S. Those Who Understand: Knowledge Growth in Teaching. Educ. Res. 1986, 15, 4-14. [CrossRef]

13. Bildungsrat Beschlüsse der Kultusministerkonferenz. Bildungsstandards im Fach Biologie für den Mittleren Schulabschluss; Luchterhand: Munich, Germany, 2004.

14. Bybee, R.W. Scientific Inquiry And Science Teaching. Sci. Inq. Nat. Sci. 2007, 1-14. [CrossRef]

15. Anderson, R. Reforming Science Teaching: What Research Says About Inquiry. J. Sci. Teacher Educ. 2002, 13, 1-12. [CrossRef]

16. Sofoklis, S.A.; Rodger, R.W.; Bogner, F.X. PATHWAYS-A Case of Large-Scale Implementation of Evidence-Based Practice in Scientific Inquiry-Based Science Education. Int. J. High. Educ. 2017, 6, 8. [CrossRef]

17. Resnick, L.B. Learning in School and out. Educ. Res. 1987, 16, 13. [CrossRef]

18. Harring, M.; Witte, M.D.; Burger, T. Informelles Lernen-Eine Einführung, 2. Auflage; Beltz Juventa in der Verlagsgruppe Beltz: Weilheim Basel, Germany, 2018; ISBN 978-3-7799-3134-8.

19. Gerber, B.L.; Marek, E.A.; Cavallo, A.M.L. Development of an informal learning opportunities assay. Int. J. Sci. Educ. 2001, 23, 569-587. [CrossRef]

20. Eshach, H. Bridging in-school and out-of-school learning: Formal, non-formal, and informal education. J. Sci. Educ. Technol. 2007, 16, 171-190. [CrossRef]

21. Vennix, J.; den Brok, P.; Taconis, R. Perceptions of STEM-based outreach learning activities in secondary education. Learn. Environ. Res. 2017, 20, 21-46. [CrossRef]

22. Deci, E.L.; Ryan, R.M. Intrinsic Motivation and Self-Determination in Human Behavior; Plenum Press: New York, NY, USA, 1985.

23. Laursen, S.; Liston, C.; Thiry, H.; Graf, J. What good is a scientist in the classroom? Participant outcomes and program design features for a short-duration science outreach intervention in $\mathrm{K}-12$ classrooms. CBE-Life Sci. Educ. 2007, 6, 49-64. [CrossRef]

24. Slavin, R.E. Cooperative learning in elementary schools. Educ. 3-13 2015, 43, 5-14. [CrossRef]

25. Fröhlich, G.; Sellmann, D.; Bogner, F.X. The influence of situational emotions on the intention for sustainable consumer behaviour in a student-centred intervention. Environ. Educ. Res. 2013, 19, 747-764. [CrossRef]

26. Schmid, S.; Bogner, F.X. Effects of Students' Effort Scores in a Structured Inquiry Unit on Long-Term Recall Abilities of Content Knowledge. Educ. Res. Int. 2015, 2015, 826734. [CrossRef]

27. Sturm, H.; Bogner, F.X. Learning at workstations in two different environments: A museum and a classroom. Stud. Educ. Eval. 2010, 36, 14-19. [CrossRef] 
28. Sturm, H.; Bogner, F.X. Student-oriented versus teacher-centred: The effect of learning at workstations about birds and bird flight on cognitive achievement and motivation. Int. J. Sci. Educ. 2008, 30, 941-959. [CrossRef]

29. Schaal, S.; Bogner, F.X. Human visual perception-Learning at workstations. J. Biol. Educ. 2005, 40, 32-37. [CrossRef]

30. Rohrbeck, C.A.; Ginsburg-Block, M.D.; Fantuzzo, J.W.; Miller, T.R. Peer-assisted learning interventions with elementary school students: A meta-analytic review. J. Educ. Psychol. 2003, 95, 240-257. [CrossRef]

31. Vygotsky, L.S. Mind In Society: Development of Higher Psychological Processes; Cole, M., John-Steiner, V., Scribner, S., Spouberman, E., Eds.; Harvard UP: Cambridge, MA, USA, 1978.

32. Piaget, J.; Gabain, M. The Language and Thought of the Child; K. Paul, Trench, Trubner \& Co., Ltd.: London, UK; Harcourt Brace \& Company, Inc.: New York, NY, USA, 1926.

33. Johnson, R.T.; Johnson, D.W. An Overview of Cooperative Learning. In Creativity and Collaborative Learning; Thousand, J., Villa, A., Nevin, A., Eds.; Brookes Press: Baltimore, MD, USA, 1994; pp. 1-21.

34. Bilgin, I. The Effects of Hands-on Activities Incorporating a Cooperative Learning Approach on Eight Grade Students' Science Process Skills and Attitudes Toward Science. J. Balt. Sci. Educ. 2006, 5, 15-25.

35. Marth, M.; Bogner, F.X. Does the issue of bionics within a student-centered module generate long-term knowledge? Stud. Educ. Eval. 2017, 55, 117-124. [CrossRef]

36. Kyndt, E.; Raes, E.; Lismont, B.; Timmers, F.; Cascallar, E.; Dochy, F. A meta-analysis of the effects of face-to-face cooperative learning. Do recent studies falsify or verify earlier findings? Educ. Res. Rev. 2013, 10, 133-149. [CrossRef]

37. Palmer, D.H. Student Interest Generated During an Inquiry Skills Lesson. J. Res. Sci. Teach. 2009, 46, 147-165. [CrossRef]

38. Hidi, S.; Renninger, K.A. The Four-Phase Model of Interest Development. Educ. Psychol. 2006, 41, 111-127. [CrossRef]

39. Faulstich, P.; Grotlüschen, A. Erfahrung und Interesse beim Lernen-Konfrontationen der Konzepte von Klaus Holzkamp und John Dewey. Forum Krit. Psychol. 2006, 50, 56-71.

40. Renninger, K.A.; Hidi, S.; Krapp, A. The role of interest in learning and development. In Proceedings of the A Matter of Interest; Schraw, G., Ed.; Lawrence Erlbaum: Mahwah, NJ, USA, 1994; p. 461.

41. Hidi, S. Interest and Its Contribution as a Mental Resource for Learning. Rev. Educ. Res. 1990, 60, 549-571. [CrossRef]

42. Renninger, K.A.; Wozniak, R.H. Effect of Interest on Attentional Shift, Recognition, and Recall in Young Children. Dev. Psychol. 1985, 21, 624-632. [CrossRef]

43. Randler, C.; Hummel, E.; Gläser-Zikuda, M.; Vollmer, C.; Bogner, F.X.; Mayring, P. Reliability and validation of a short scale to measure situational emotions in science education. Int. J. Environ. Sci. Educ. 2011, 6, 359-370.

44. Randler, C.; Bogner, F.X. Pupils' interest before, during, and after a curriculum dealing with ecological topics and its relationship with achievement. Educ. Res. Eval. 2007, 13, 463-478. [CrossRef]

45. Hidi, S. Interest: A unique motivational variable. Educ. Res. Rev. 2006, 1, 69-82. [CrossRef]

46. Mitchell, M. Situational Interest: Its Multifaceted Structure in the Secondary School Mathematics Classroom. J. Educ. Psychol. 1993, 85, 424-436. [CrossRef]

47. Keller, J.M. Motivational design of instruction. Instr. Des. Theor. Model. An Overv. Their Curr. Status 1983, 1, 383-434.

48. Frymier, A.B.; Shulman, G.M. "What's in it for me?": Increasing content relevance to enhance students' motivation. Commun. Educ. 1995, 44, 40-50. [CrossRef]

49. Gilman, R.; Anderman, E.M. Motivation and its relevance to school psychology: An introduction to the special issue. J. Sch. Psychol. 2006, 44, 325-329. [CrossRef]

50. Albrecht, J.R.; Karabenick, S.A. Relevance for Learning and Motivation in Education. J. Exp. Educ. 2018, 86, 1-10. [CrossRef]

51. Alexander, P.A. The Relevance of Relevance for Learning and Performance. J. Exp. Educ. 2018, 86, 124-135. [CrossRef]

52. National Research Council. Engaging Schools: Fostering High School Students; Motivation to Learn; The National Academies Press: Washington, DC, USA, 2004. [CrossRef] 
53. Newby, T.J. Classroom Motivation: Strategies of First-Year Teachers. J. Educ. Psychol. 1991, 83, $195-200$. [CrossRef]

54. Hill, R.J. The Measurement of Meaning. Am. Sociol. Rev. 1958, 23, 227-228. [CrossRef]

55. Schönfelder, M.L.; Bogner, F.X. Individual perception of bees: Between perceived danger and willingness to protect. PLoS ONE 2017, 12, e0180168. [CrossRef]

56. Osgood, C.E.; May, W.H.; Miron, M.S.; Miron, M.S. Cross-Cultural Universals of Affective Meaning; University of Illinois Press: Urbana, IL, USA, 1975; Volume 1.

57. Osgood, C.E. Studies on the generality of affective meaning systems. Am. Psychol. 1962, 17, 10-28. [CrossRef]

58. Schiefele, U. Interest, Learning, and Motivation. Educ. Psychol. 1991, 26, 299-323.

59. Field, A. Discovering Statistics using IBM SPSS Statistics, 4th ed.; Carmichael, M., Ed.; Sage Publications: London, UK; Los Angeles, CA, USA; New Dehli, India; Singapore; Washington, DC, USA, 2013. [CrossRef]

60. Kaiser, H.F. A Second-generation Little Jiffy. Psychometrika 1970, 35, 401-415. [CrossRef]

61. Bogner, F.X.; Fremerey, C. How outreach learning at authentic waste management environments interacts with cognitive knowledge dimensions. J. Wastemanag. Environ. Issues 2017, I, 1-10.

62. Tennyson, R.D.; Rasch, M. Linking cognitive learning theory to instructional prescriptions. Instr. Sci. 1988, 17, 369-385. [CrossRef]

63. Müller, F.H. Interesse und Lernen. ZfW 2006, 1, 48-62.

64. Värlander, S. The role of students' emotions in formal feedback situations. Teach. High. Educ. 2008, 13, 145-156. [CrossRef]

65. Pekrun, R.; Goetz, T.; Daniels, L.M.; Stupnisky, R.H.; Perry, R.P. Boredom in Achievement Settings: Exploring Control-Value Antecedents and Performance Outcomes of a Neglected Emotion. J. Educ. Psychol. 2010, 102, 531-549. [CrossRef]

66. Gibson, H.L.; Chase, C. Longitudinal Impact of an Inquiry-Based Science Program on Middle School Students' Attitudes Toward Science. Sci. Educ. 2002, 86, 693-705. [CrossRef]

67. Fremerey, C.; Bogner, F.X. Learning about Drinking Water: How Important are the Three Dimensions of Knowledge that Can Change Individual Behavior? Educ. Sci. 2014, 4, 213-228. [CrossRef]

68. Bogner, F.X. The Influence of Short-Term Outdoor Ecology Education on Long-Term Variables of Environmental Perspective. J. Environ. Educ. 1998, 29, 17-29. [CrossRef]

69. Fremerey, C.; Bogner, F.X. Cognitive learning in authentic environments in relation to green attitude preferences. Stud. Educ. Eval. 2015, 44, 9-15. [CrossRef]

70. Johnson, B.; Manoli, C. The 2MEV Scale in the United States: A Measure of Children's Environmental Attitudes Based on the Theory of Ecological Attitude. J. Environ. Educ. 2010, 42, 84-97. [CrossRef]

71. Fančovičová, J.; Prokop, P. Plants have a chance: Outdoor educational programmes alter students' knowledge and attitudes towards plants. Environ. Educ. Res. 2011, 17, 537-551. [CrossRef]

72. Sellmann, D.; Bogner, F.X. Climate change education: quantitatively assessing the impact of a botanical garden as an informal learning environment. Environ. Educ. Res. 2013, 19, 415-429. [CrossRef]

73. Stein, S.J.; Isaacs, G.; Andrews, T. Incorporating authentic learning experiences within a university course. Stud. High. Educ. 2004, 29, 239-258. [CrossRef]

74. Sellmann, D.; Bogner, F.X. Effects of a 1-day environmental education intervention on environmental attitudes and connectedness with nature. Eur. J. Psychol. Educ. 2013, 28, 1077-1086. [CrossRef]

75. Bissinger, K.; Bogner, F.X. Environmental literacy in practice: education on tropical rainforests and climate change. Environ. Dev. Sustain. 2018, 20, 2079-2094. [CrossRef]

76. National Research Council. How People Learn: Brain, Mind, Experience, and School: Expanded Edition; The National Academies Press: Washington, DC, USA, 2000. [CrossRef]

77. Goldschmidt, M.; Scharfenberg, F.J.; Bogner, F.X. Instructional efficiency of different discussion approaches in an outreach laboratory: Teacher-guided versus student-centered. J. Educ. Res. 2016, 109, 27-36. [CrossRef]

78. Blumenfeld, P.C.; Soloway, E.; Marx, R.W.; Krajcik, J.S.; Guzdial, M.; Palincsar, A. Motivating Project-Based Learning: Sustaining the Doing, Supporting the Learning. Educ. Psychol. 1991, 26, 369-398.

79. Graham, S.; Golan, S. Motivational Influences on Cognition: Task Involvement, Ego Involvement, and Depth of Information Processing. J. Educ. Psychol. 1991, 83, 187-194. [CrossRef]

80. Johnson, D.W.; Johnson, R.T. Making Cooperative Learning Work. Theory Pract. 1999, 38, 67-73. [CrossRef] 
81. Mayer, R.E. Should There Be a Three-Strikes Rule against Pure Discovery Learning? The Case for Guided Methods of Instruction. Am. Psychol. 2004, 59, 14-19. [CrossRef]

82. Poppenk, J.; Köhler, S.; Moscovitch, M. Revisiting the novelty effect: When familiarity, not novelty, enhances memory. J. Exp. Psychol. Learn. Mem. Cogn. 2010, 36, 1321-1330. [CrossRef]

(C) 2020 by the authors. Licensee MDPI, Basel, Switzerland. This article is an open access article distributed under the terms and conditions of the Creative Commons Attribution (CC BY) license (http://creativecommons.org/licenses/by/4.0/). 